\title{
Targeting Implicit Approach Reactions to Snack Food in Children: Effects on Intake
}

Article in Health Psychology · August 2016

DOI: $10.1037 /$ hea0000365

CITATIONS

2

3 authors, including:

Frans Folkvord

Radboud University

15 PUBLICATIONS 62 CITATIONS

SEE PROFILE
READS

34

Harm Veling

Radboud University

40 PUBLICATIONS 723 CITATIONS

SEE PROFILE

All content following this page was uploaded by Harm Veling on 23 August 2016. 


\title{
Targeting Implicit Approach Reactions to Snack Food in Children: Effects on Intake
}

\author{
Frans Folkvord \\ Radboud University Nijmegen and Open University of Catalonia
}

\author{
Harm Veling \\ Radboud University Nijmegen
}

\author{
Hans Hoeken \\ Utrecht University
}

\begin{abstract}
Objective: Implicit approach reactions to energy-dense snack food can facilitate unhealthy eating in children. Therefore, an experiment was conducted to test whether modifying implicit reactions to snack food by means of a go/no-go task can reduce consumption of this food. The effectiveness of this intervention on actual snack intake after exposure to a food or a control advertisement was tested. Method: Children (133; age range $=7-10$ years) played an advergame promoting either energy-dense food or nonfood products. Subsequently, children conducted either a go/no-go food task in which the advertised food was consistently associated with no-go cues, or a go/no-go control task in which colored circles were consistently associated with no-go cues. Afterward, they could eat the advertised food and a new food. Candy intake was weighed and caloric intake was determined. Results: Results show that children who performed the go/no-go food task consumed significantly and considerably fewer calories (34\%) than the children who carried out the control task. No main effect of type of advertisement was found. Furthermore, the effect of the go/no-go food task was similar after each type of advertisement, similar for advertised and new foods, and was significant for both girls and boys. Conclusion: Targeting implicit reactions to high-energy snacks proved effective in decreasing intake of snacks in children. Furthermore, the previously reported stimulating effect of food promoting advergames on intake may disappear when a short cognitive task is presented directly after the game. Future work should evaluate the clinical implications of these findings.
\end{abstract}

Keywords: implicit approach reactions, snack food intake, children, food advertisements, obesity, intervention

Supplemental materials: http://dx.doi.org/10.1037/hea0000365.supp

Rates of childhood obesity have increased at an alarming degree in recent years (Ogden, Carroll, Kit, \& Flegal, 2014). There is growing evidence that overconsumption of high calorie food is a major contributor to this trend (Poti, Duffey, \& Popkin, 2014). Therefore, it is important to develop interventions to curb children's unhealthy eating behavior. Prominent interventions mostly focus on explicit factors, and have had only limited success (Sobol-Goldberg, Rabinowitz, \& Gross, 2013), possibly because they fail to directly target implicit associative processes that stimulate overeating. Specifically, contemporary self-regulation mod-

Frans Folkvord, Behavioral Science Institute, Communication Science, Radboud University Nijmegen and Applied Social Science and Behavioral Economics Research Group, Open University of Catalonia; Harm Veling, Behavioral Science Institute, Social and Cultural Psychology, Radboud University Nijmegen; Hans Hoeken, Utrecht Institute of Linguistics OTS, Utrecht University.

We thank Daan van Someren for his help with the data collection.

Correspondence concerning this article should be addressed to Frans Folkvord, Behavioral Science Institute, Radboud University Nijmegen, Thomas van Aquinostraat 2, 6526 GD Nijmegen, The Netherlands. E-mail: f.folkvord@maw.ru.nl els suggest that eating behavior is often influenced by implicit associative cognitive processes, that can motivate behavior with respect to food in an impulsive and difficult to control way (Hofmann, Friese, \& Wiers, 2008; Strack \& Deutsch, 2004). Gaining control over these processes seems important for limiting caloric intake.

Scholars and health practitioners have started to search for intervention techniques that target implicit eating-related processes (e.g., Marteau, Hollands, \& Fletcher, 2012; Sheeran, Gollwitzer, \& Bargh, 2013) and change immediate attentional, affective, or behavioral responses to food stimuli by means of training procedures (Kemps, Tiggemann, Orr, \& Grear, 2014). One example is a go/no-go task in which food images are consistently paired with no-go cues (Houben \& Jansen, 2011). In adults, this task leads to devaluation of the presented food, and reduces consumption of and choices for this food (Lawrence, Verbruggen, Morrison, Adams, \& Chambers, 2015; Veling, Aarts, \& Stroebe, 2013).

The effectiveness of the go/no-go task as an intervention to reduce food intake among children has remained unexplored, whereas applying this intervention among children is important because of two reasons. First, children, just like adults, have strong appetitive reactions toward palatable foods (van Meer, van der Laan, Adan, Viergever, \& Smeets, 2015), but at the same time a 
less developed inhibition system (Nederkoorn, Coelho, Guerrieri, Houben, \& Jansen, 2012; Williams, Ponesse, Schachar, Logan, \& Tannock, 1999). Therefore, it is currently unclear whether this intervention will decrease intake among children, or will only work for older participants with a more developed inhibition system. Second, decreasing implicit approach responses to unhealthy food at an early age could possibly affect eating behavior at a later stage (Birch \& Fisher, 1998).

The first aim of this experiment was to test whether the go/no-go task can reduce unhealthy snack consumption by children. Associating energy-dense snacks with no-go cues in a go/no-go task was expected to decrease caloric intake (H1). Moreover, children are frequently exposed to online digital games that are used to advertise energy-dense snacks or a candy-brand (Culp, Bell, \& Cassady, 2010), so called food "advergames." Food advergames appear to stimulate impulsive (Hofmann et al., 2008) eating behavior, as increased intake after playing the game is observed independent of hunger or intentions to consume food (Folkvord, Anschütz, Buijzen, \& Valkenburg, 2013; Folkvord, Anschütz, Nederkoorn, Westerik, \& Buijzen, 2014). Furthermore, the go/ no-go task is assumed to be particularly effective in reducing impulsive eating behavior (for a discussion see Veling, Van Koningsbruggen, Aarts, \& Stroebe, 2014). Hence, the effect of the go/no-go task was expected to be stronger after playing a food advergame than after playing a nonfood advergame (H2).

\section{Method}

\section{Participants and Design}

Participants were 133 children (age: $7-10$ years, $M=8.9, S D=$ 1.0). A mixed design was used, with type of advergame (food or nonfood) and go/no-go task (food or control) as between-subjects factors, and type of candy (advertised or new) as a within-subjects factor. Between-subjects conditions were randomized within three schools and the conditions were counterbalanced, so that none of the conditions were tested more often in the morning or just before or after the break. Children were tested individually at their schools during regular school hours from February 2014 until June 2014. The experimenter collected one child at a time from the classroom (in alphabetical order). The faculty's committee for ethical concerns approved the study. It was emphasized to the parents and the children beforehand that the data would remain confidential and that children could cease participation at any moment. Around $93 \%$ of the children were allowed to participate. The teacher was asked to prevent children from discussing the study in class.

\section{Manipulations}

Food advertisement. Children played either an energy-dense food advergame (i.e., a memory-game promoting a popular candy brand on the backside of the cards and eight different sweets [i.e., jelly cola bottles] from this brand on the flipside of the cards), or a nonfood advergame (i.e., a memory-game promoting a popular Dutch toy brand and eight individual toys from this brand). Instructions were read out loud by the experimenter. The memorygame is a game whereby children were asked to match two identical cards by clicking on them with the mouse (cards turned upon clicking). After selecting two cards, a positive sound was played if the cards were identical and a negative sound if they were not identical. Irrespective of the outcome, children received a new set with cards being in new positions. Children played five rounds with 10 opportunities to match two cards in each round (see Supplementary Materials for further information).

Go/no-go task. Children saw a short instruction screen stating that their task was to press the space bar when a blue border would appear around an image (go trials), and refrain from responding when a gray border appeared (no-go trials). Children were instructed to react as quickly as possible while making as few errors as possible. The border color appeared $100 \mathrm{~ms}$ after image onset (and remained visible during the trial). The image was presented for 1,000 ms or until a response was registered. After an erroneous (non)response, a red cross was presented for $500 \mathrm{~ms}$. The intertrial interval was $500 \mathrm{~ms}$ (see Veling et al., 2014).

The go/no-go task consisted of 132 trials (66 go trials). In both conditions 22 images of cute animals (e.g., kitten, rabbit) were each presented three times on go trials. In the food condition, 22 different images of jelly candy were each presented three times on no-go trials whereas in the control condition 22 colored circles were each presented three times on no-go trials. Task duration was approximately $5 \mathrm{~min}$.

\section{Measure of Intake}

Children were allowed to eat ad libitum from two bowls, one containing $500 \mathrm{~g}$ of jelly cola bottles (advertised food) and the other $500 \mathrm{~g}$ of milk chocolate candy shells (new food). Previous studies (Folkvord et al., 2013, 2014) have shown that advergames promoting energy-dense snack food increase snack intake of both advertised and nonadvertised (new) food. The amount of snack food was weighed before and after each child was given the opportunity to eat, and later translated into calories.

\section{Procedure and Analyses Strategy}

In a separate classroom, children started with a questionnaire assessing demographic questions. Children also indicated their feeling of hunger on a visual analogue scale (ranging from not hungry at all to very hungry). This question was masked by questions about felt levels of excitement, energy, and tiredness. Subsequently, children played one of the advergames for approximately $3 \mathrm{~min}$. Next, children performed the go/no-go task on a different computer. Afterward, children were led to a different table with two bowls containing the (advertised) jelly candy and the new candy, and a glass of water. The experimenter explained to the child that (s)he would have a break for $5 \mathrm{~min}$ and (s)he could eat as much as (s)he wanted. After the break, the experimenter entered the room again and children finished the second part of the questionnaire, which consisted of questions assessing candy liking, attitudes to the advergame and products in the advergame, and children's impressions of the purpose of the study (see Supplementary Materials for further information on these measures). Then, the experimenter measured the height and weight of the children. Finally, the experimenter asked children to refrain from discussing the experiment with their classmates. The experimenter refilled and weighed the bowls before the next child entered the room. 
To test the hypotheses, a general linear model (GLM) analysis was performed on total intake (in calories) with type of advergame and go/no-go task (and their interaction) as between subjects factors. Moreover, to further evaluate evidence with regard to the hypotheses, a Bayesian ANOVA was performed on intake. Post hoc tests were conducted for exploratory purposes to assess for sex differences. Two-tailed analyses tests were used, the $p$ value was considered significant at .05 . Cohen's $d$ was calculated as a measure of effect size.

\section{Results}

No differences between the experimental conditions for performance on the go/no-go task, sex, hunger, BMI, age, liking of the two kinds of candy were found. Therefore, these variables were not included in our models. Nonetheless, the main analyses provide similar significant results when controlling for these variables. Means and standard deviations for all variables are presented for each condition separately in Supplementary Table 1c, and correlations between the variables are presented in Supplementary Table 2 .

Results from the GLM showed that the go/no-go task had a significant effect on total intake, $F(1,129)=6.32, p=.01$, Cohen's $d=0.44$ (see Figure 1). Children in the go/no-go food condition $(M=169.6 \mathrm{kcal}, S D=117.0 \mathrm{kcal})$ ate significantly less than children in go/no-go control condition $(M=226.0 \mathrm{kcal}, S D=$ $142.2 \mathrm{kcal})$, thereby confirming H1. The main effect of type of advergame was not significant, $F(1,129)=0.10, p=.75$, nor was the interaction between the go/no-go task and type of advergame, $F(1,129)=0.30, p=.58$. Results of an additional Bayesian ANOVA were consistent with these results and supported evidence for the effect of go/no-go task $\left(\mathrm{BF}_{10}=3.11\right)$, and indicated evidence against the effect of type of advergame $\left(\mathrm{BF}_{10}=0.19\right)$ and against the interaction effect $\left(\mathrm{BF}_{10}=0.28\right.$; see Supplementary Materials for more details on this analysis).

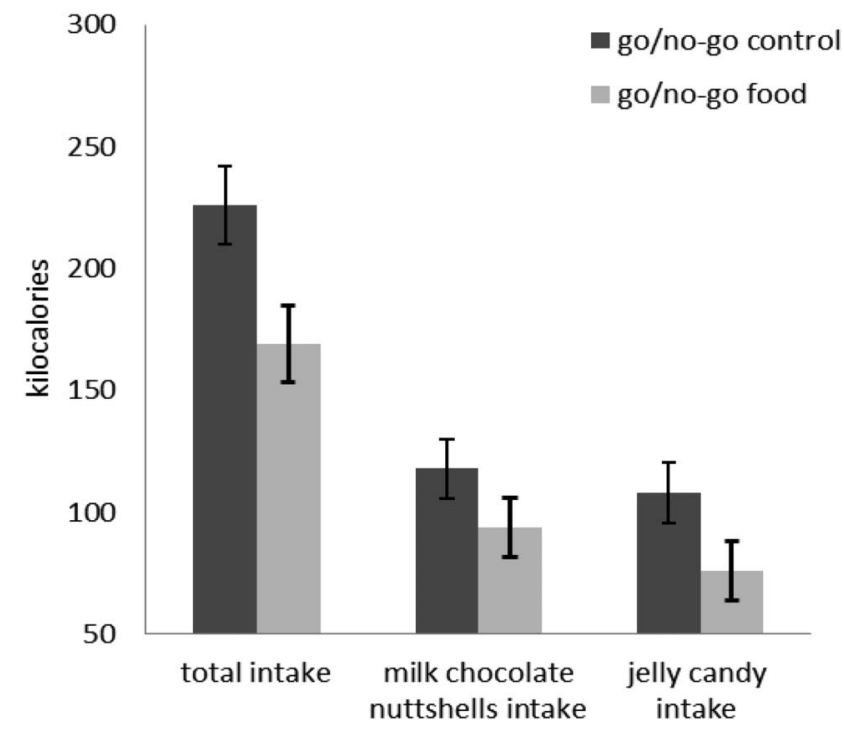

Figure 1. Mean snack intake in kilocalories as a function of go/no-go task and type of candy. Error bars represent $S E$.
Additional explorative analyses showed that the effect of the go/no-go task on total caloric intake was significant for both girls, $F(1,69)=4.09, p=.05$, Cohen's $d=0.50$, and for boys, $F(1$, 61 ) $=4.67, p=.04$, Cohen's $d=0.55$ (see Supplementary Materials for the descriptive information).

\section{Discussion}

Previous studies have shown that a short go/no-go task can reduce eating behavior among adults (Houben \& Jansen, 2011; Lawrence et al., 2015). The current findings support the hypothesis that the go/no-go task is effective in reducing snack intake among children. This is an important finding because children have the same strong approach intentions toward palatable food as adults (van Meer et al., 2015), but their inhibition system is still developing (Nederkoorn et al., 2012; Williams et al., 1999). Hence, the results suggest the effectiveness of the go/no-go task is not contingent on having a fully developed inhibition system, and that approach reactions can be targeted at an early age.

Type of advertisement did not influence intake as a main effect nor did it interact with the go/no-go task. In contrast to previous studies that did find main effects of advertisements on intake (Boyland \& Halford, 2013; Folkvord et al., 2013, 2014; Harris, Speers, Schwartz, \& Brownell, 2012), children in the current study could not eat while or immediately after the advertisement because they carried out the go/no-go task before they had the opportunity to eat. Performing a task between a food advergame and eating opportunity may decrease the influence of the advergame on intake (cf. Skorka-Brown, Andrade, \& May, 2014). However, compared with previous studies (Folkvord et al., 2013, 2014), a slightly different and shorter version of the advertisement was used. Therefore, it remains to be tested whether the go/no-go task can counteract effects of other types of advertising. Analyses also showed that the go/no-go task reduced snack intake for both sexes, which is noteworthy considering that participants in previous studies were mostly (Lawrence et al., 2015), or exclusively (Houben \& Jansen, 2011) women.

Strengths of this study are the measurement of actual food intake, and the generalization of the effectiveness of the go/no-go task to reducing food intake among children. One limitation of this study is that we only examined immediate effects of the go/no-go task. Research in adults suggests effects of a single session may last for a week (Veling et al., 2014), but more systematic research is needed. In addition, the findings from this study could be used for further research that tries to identify individual factors (e.g., implicit associative processes) that make children more vulnerable to overconsumption. Next, more research is needed to examine if the go/no-go task is also effective outside of experimental situations. Altogether, more research is needed to evaluate the clinical implications. Finally, the results do not shed light on the mechanism that is responsible for the go/no-go task's success in reducing food intake by children. Previous work in adults suggests that food devaluation is a likely mechanism (Veling et al., 2013).

To conclude, the results show that targeting implicit processes of eating behavior can be effective in curbing the intake of highenergy snacks by children. This study offers evidence that modifying implicit processes can help to reduce unhealthy eating in children. Previous findings showing that the go/no-go task intervention can eventually facilitate weight loss (Veling et al., 2014) 
suggest this approach may be a promising avenue to explore further

\section{References}

Birch, L. L., \& Fisher, J. O. (1998). Development of eating behaviors among children and adolescents. Pediatrics, 101, 539-549.

Boyland, E. J., \& Halford, J. C. (2013). Television advertising and branding. Effects on eating behaviour and food preferences in children. Appetite, 62, 236-241. http://dx.doi.org/10.1016/j.appet.2012.01.032

Culp, J., Bell, R. A., \& Cassady, D. (2010). Characteristics of food industry web sites and "advergames" targeting children. Journal of Nutrition Education and Behavior, 42, 197-201. http://dx.doi.org/10.1016/j.jneb .2009 .07 .008

Dienes, Z. (2014). Using Bayes to get the most out of non-significant results. Frontiers in Psychology, 5, 781. http://dx.doi.org/10.3389/fpsyg .2014 .00781

Folkvord, F., Anschütz, D. J., Buijzen, M., \& Valkenburg, P. M. (2013). The effect of playing advergames that promote energy-dense snacks or fruit on actual food intake among children. The American Journal of Clinical Nutrition, 97, 239-245. http://dx.doi.org/10.3945/ajen.112 .047126

Folkvord, F., Anschütz, D. J., Nederkoorn, C., Westerik, H., \& Buijzen, M. (2014). Impulsivity, "advergames," and food intake. Pediatrics, 133, 1007-1012. http://dx.doi.org/10.1542/peds.2013-3384

Harris, J. L., Speers, E. S., Schwartz, M. B., \& Brownell, K. D. (2012). U.S. food company branded advergames on the internet: Children's exposure and effects on snack consumption. Journal of Children and Media, 6, 51-68. http://dx.doi.org/10.1080/17482798.2011.633405

Hofmann, W., Friese, M., \& Wiers, R. W. (2008). Impulsive versus reflective influences on health behavior: A theoretical framework and empirical review. Health Psychology Review, 2, 111-137. http://dx.doi .org/10.1080/17437190802617668

Houben, K., \& Jansen, A. (2011). Training inhibitory control. A recipe for resisting sweet temptations. Appetite, 56, 345-349. http://dx.doi.org/10 1016/j.appet.2010.12.017

Kemps, E., Tiggemann, M., Orr, J., \& Grear, J. (2014). Attentional retraining can reduce chocolate consumption. Journal of Experimental Psychology: Applied, 20, 94-102. http://dx.doi.org/10.1037/xap0000005

Lawrence, N. S., Verbruggen, F., Morrison, S., Adams, R. C., \& Chambers, C. D. (2015). Stopping to food can reduce intake. Effects of stimulusspecificity and individual differences in dietary restraint. Appetite, 85, 91-103. http://dx.doi.org/10.1016/j.appet.2014.11.006

Love, J., Selker, R., Marsman, M., Jamil, T., Verhagen, A. J., Ly, A., . . Wagenmakers, E.-J. (2015). JASP (Version 0.6.6) [Computer software].

Marteau, T. M., Hollands, G. J., \& Fletcher, P. C. (2012). Changing human behavior to prevent disease: The importance of targeting automatic processes. Science, 337, 1492-1495. http://dx.doi.org/10.1126/science $\underline{.1226918}$
Nederkoorn, C., Coelho, J. S., Guerrieri, R., Houben, K., \& Jansen, A. (2012). Specificity of the failure to inhibit responses in overweight children. Appetite, 59, 409-413. http://dx.doi.org/10.1016/j.appet.2012 .05 .028

Ogden, C. L., Carroll, M. D., Kit, B. K., \& Flegal, K. M. (2014). Prevalence of childhood and adult obesity in the United States, 2011-2012. Journal of the American Medical Association, 311, 806-814. http://dx .doi.org/10.1001/jama.2014.732

Poti, J. M., Duffey, K. J., \& Popkin, B. M. (2014). The association of fast food consumption with poor dietary outcomes and obesity among children: Is it the fast food or the remainder of the diet? The American Journal of Clinical Nutrition, 99, 162-171. http://dx.doi.org/10.3945/ ajen.113.071928

Sheeran, P., Gollwitzer, P. M., \& Bargh, J. A. (2013). Nonconscious processes and health. Health Psychology, 32, 460-473. http://dx.doi .org/10.1037/a0029203

Skorka-Brown, J., Andrade, J., \& May, J. (2014). Playing "Tetris" reduces the strength, frequency and vividness of naturally occurring cravings. Appetite, 76, 161-165. http://dx.doi.org/10.1016/j.appet.2014.01.073

Sobol-Goldberg, S., Rabinowitz, J., \& Gross, R. (2013). School-based obesity prevention programs: A meta-analysis of randomized controlled trials. Obesity, 21, 2422-2428. http://dx.doi.org/10.1002/oby.20515

Strack, F., \& Deutsch, R. (2004). Reflective and impulsive determinants of social behavior. Personality and Social Psychology Review, 8, 220-247. http://dx.doi.org/10.1207/s15327957pspr0803_1

van Meer, F., van der Laan, L. N., Adan, R. A., Viergever, M. A., \& Smeets, P. A. (2015). What you see is what you eat: An ALE metaanalysis of the neural correlates of food viewing in children and adolescents. NeuroImage, 104, 35-43. http://dx.doi.org/10.1016/j neuroimage.2014.09.069

Veling, H., Aarts, H., \& Stroebe, W. (2013). Stop signals decrease choices for palatable foods through decreased food evaluation. Frontiers in Psychology, 4, 875. http://dx.doi.org/10.3389/fpsyg.2013.00875

Veling, H., van Koningsbruggen, G. M., Aarts, H., \& Stroebe, W. (2014). Targeting impulsive processes of eating behavior via the internet. Effects on body weight. Appetite, 78, 102-109. http://dx.doi.org/10.1016/j.appet .2014.03.014

Wetzels, R., Grasman, R. P., \& Wagenmakers, E. J. (2012). A default Bayesian hypothesis test for ANOVA designs. The American Statistician, 66, 104-111. http://dx.doi.org/10.1080/00031305.2012.695956

Williams, B. R., Ponesse, J. S., Schachar, R. J., Logan, G. D., \& Tannock, R. (1999). Development of inhibitory control across the life span. Developmental Psychology, 35, 205-213. http://doi/10.1037/0012-1649 .35 .1 .205

Received February 10, 2015

Revision received February 4, 2016

Accepted February 10, 2016 